\title{
Migration practitioners' roles in communicating credible refugee claims
}

\section{Laura Smith-Khan}

\begin{abstract}
This article explores the important communicative roles that Australian migration lawyers and agents play when assisting refugee visa applicants, with particular attention to how they contribute to the (re)construction of applicant credibility. It identifies a range of communicative choices and concludes that practitioners have a variety of individual beliefs and skills that lead them to participate in applications and appeals in diverse ways. This indicates the potential for diverse experiences and outcomes for individual asylum-seekers based on the assistance they have.
\end{abstract}

\section{Keywords}

Refugees/asylum seekers, linguistics, immigration, tribunals, language management, communicative resources, lawyers and the legal system

Corresponding author: Dr Laura Smith-Khan, Faculty of Law, University of Technology Sydney, Australia

Email: Laura.Smith-Khan@uts.edu.au

Credibility assessments are a common, yet much-critiqued component of refugee status determination $(R S D)$. However, the copious literature on these assessments rarely examines the role of migration lawyers in helping to establish and defend credibility, or seeking to reclaim it. Similarly, government guidance has little to say about how legal assistance affects applicant credibility. ${ }^{1}$ Studies interested in legal assistance in the United Kingdom and United States suggest that quality advice and representation play a crucial role in creating credible refugee applications, and more broadly increasing application success rates. ${ }^{2}$

\footnotetext{
${ }^{1}$ Laura Smith-Khan, 'Telling Stories: Credibility and the representation of social actors in Australian asylum appeals' (2017) 28(5) Discourse \& Society 512; Laura Smith-Khan, 'Different in the same way? Language, diversity and refugee credibility' (2017) 29(3) International Journal of Refugee Law 389.

${ }^{2}$ Jessica Hambly, 'Interactions and Identities in UK Asylum Appeals: Lawyers and Law in a Quasi-Legal Setting' in Nick Gill and Anthony Good (eds), Asylum Determination in Europe: Ethnographic Perspectives (Palgrave Macmillan, 2019) 195; Andrew I Schoenholtz, Philip G Schrag and Jaya Ramji-Nogales, Lives in the Balance: Asylum Adjudication by the Department of Homeland Security (NYU Press, 2014); Carol Bohmer and Amy Shuman, Rejecting Refugees: Political Asylum in the 21st Century (Routledge, 2007).
} 
In Australia, Registered Migration Agents (RMAs) work with some of the most complex and restrictive asylum laws worldwide, with a range of deterrence-focused policies aimed at discouraging boat arrivals. ${ }^{3}$ While avenues to gain protection are particularly limited for those coming by boat, individuals who arrive with a visa may apply for a permanent 'protection visa'. This involves, firstly, submitting to the Immigration Department ${ }^{4}$ correctly completed prescribed application forms. These require disclosure of a wide range of demographic information and travel, education and employment history, as well as outlining the reasons for seeking protection. Applicants who successfully complete and submit a valid application will be assigned a case officer within the Immigration Department and invited to attend an interview, where they will be asked for further details and questioned about their persecution-related claims. ${ }^{5}$ If their application is unsuccessful, they will receive a written notification and reasons explaining the decision. Applicants may seek a review of negative decisions at the Migration and Refugee Division of the Administrative Appeals Tribunal (AAT), once again, involving providing a further written submission, outlining the merits of their claim and any new or further information relating to these, and then attending and participating in a tribunal hearing.

At both the initial application and merits review stages, credibility is an important consideration. This is largely because refugee claims rely heavily on the story or expressed fears of the applicant, and there is often little documentary evidence to prove these fears or experiences. This has meant that determining whether their testimony is believable often becomes a key factor in deciding whether or not someone is in need of protection as a refugee. Credibility is generally assessed against multiple indicators. These include considering whether the applicant is internally consistent (that is, says the same thing over time, within and across different written documents and interviews) and externally consistent or plausible (what they claim aligns with

\footnotetext{
${ }^{3}$ Daniel Ghezelbash, 'Lessons in Exclusion: Interdiction and Extraterritorial Processing of Asylum Seekers in the United States and Australia' in Jean-Pierre Gauci, Mariagiulia Giuffré and Evangelia (Lilian) Tsourdi (eds), Exploring the Boundaries of Refugee Law: Current Protection Challenges (Brill Nijhoff, 2015) 90-117. For an explanation of boat arrivals policy see Joyce Chia, Jane McAdam and Kate Purcell, 'Asylum in Australia: Operation Sovereign Borders and International Law' (2014) 32 Australian Yearbook of International Law 33; Emily McDonald and Maria O'Sullivan, 'Protecting Vulnerable Refugees: Procedural fairness in the Australian fast track regime' (2018) 41(3) UNSW Law Journal 1003.

${ }^{4}$ The name of the relevant department changes regularly, generally with changes of government. In 2019, it is called the Department of Immigration and Border Protection, and falls within the broad-spanning Department of Home Affairs.

${ }^{5}$ Migration Act 1958 s 36.
} 
official information about their country and group of origin and decision-makers' expectations about likely behaviour). Decision-makers also consider whether applicants' claims and responses are provided in sufficient detail and whether there is a delay in making a claim, or providing information about a claim. They may also refer to demeanour as a reason for (dis)believing an applicant. ${ }^{6}$

This article draws on qualitative interviews with eight RMAs from Sydney and Melbourne, who assist in applications and AAT appeals, conducted as part of a larger study on refugee credibility. ${ }^{7}$ The interviews explored RMAs' understandings of the role(s) they play in the RSD process and the (re)construction of credibility. While this small sample in no way represents the profession as a whole, the variability of approaches, experiences and beliefs reported by this small group provides insights into the scope for diversity in the provision of migration assistance. ${ }^{8}$

\section{RMAs' communicative roles in credible applications and appeals}

Credibility is central to many refugee applications. In line with the literature, research participants suggested that 'it's a rare case that doesn't have a credibility issue' (P06) and explained how, even where other issues arise, credibility frequently features in reasons for rejecting a claim. Some participants emphasised the procedural and legal advantages for decisions relying on credibility findings, describing this as the way to avoid oversight' (P01), since these generally cannot be scrutinised at the level of judicial review, and thereby providing decision-makers with a way to avoid court

\footnotetext{
${ }^{6}$ For Australian examples highlighting the centrality of credibility assessments in RSD and critically examining the application of these indicators, see Guy Coffey, 'The Credibility of Credibility Evidence at the Refugee Review Tribunal' (2003) 15 International Journal of Refugee Law 377; Trish Luker, 'Decision Making Conditioned by Radical Uncertainty: Credibility assessment at the Australia Refugee Review Tribunal' (2013) 25(3) International Journal of Refugee Law 502; Anthea Vogl, 'Telling Stories from Start to Finish: Exploring the Demand for Narrative in Refugee Testimony' (2013) 22(1) Griffith Law Review 63. Official guidance on the application of these indicators is provided to AAT members: AAT Migration and Refugee Division Guidelines on the Assessment of Credibility (2015) https://www.aat.gov.au/landing-pages/practice-directions-guides-andguidelines/guidelines-on-assessment-of-credibility. Departmental officers are guided by policy documents, including Department of Home Affairs (Cth), Procedures Advice Manual 3: 'The Protection Visa Processing Guidelines' (30 August 2019). See para 3.50, which includes 'inconsistencies, contradictions or omissions', 'implausible, vague or incoherent claims', 'demeanour', and 'delay in claiming refugee status or presenting other information'. Part 12 - Assessing credibility), and the 'Refugee Law Guidelines (Part 15 Credibility).

${ }^{7}$ Laura Smith-Khan, Contesting Credibility in Australian Refugee Visa Decision Making and Public Discourse (Doctoral thesis, Macquarie University, 2018) https://www.languageonthemove.com/wpcontent/uploads/2019/02/Smith-Khan-2018-Contesting-Credibility-Final-PhD-Thesis.pdf.

${ }^{8}$ For a larger discussion of the value of the discursive analysis of qualitative interviews see Pirjo Nikander, 'Interviews as Discourse Data' in Gubrium et al (eds), The SAGE Handbook of Interview Research: The Complexity of the Craft (SAGE Publications, 2014) 397.
} 
remittals that would otherwise reflect badly on their professional record. ${ }^{9}$ Against this background, the interviews explored how credibility issues may arise, and the roles RMAs played to avoid or address such problems. Specifically, participants identified a range of ways in which their communicative choices or the way they managed other persons' communication were important for credibility.

\section{RMAs as communicators}

The research participants highlighted how they directly contribute to what is communicated in an application or appeal, by drafting submissions, completing applications forms, writing statutory declarations, and sometimes making oral submissions in interviews or hearings. They explained how, with information they obtain from the clients, they are primarily responsible for the drafting of all the main written documents for the application or appeal, thus impacting how the credibility indicators are assessed, as these all relate to how the refugee narrative is communicated, or queries are responded to.

Foregrounding their value in these processes sometimes involved providing comparisons with unrepresented individuals. For example, some described how, even though the protection visa application form provides a box for applicants to summarise persecution-related fears, RMAs would generally prepare a separate statement or statutory declaration from the applicant, and also write a stand-alone separate submission, going into greater detail and explicitly linking the applicant's experiences with relevant law, and third-party country information.

P01 They're not going to attach anything. They're just going to fill out the form and that means that you use those spaces for the description of some of the most important [...] issues. And when the department expects that written piece to be more detailed, but doesn't provide enough space for it ... then, you're kind of misleading applicants. ${ }^{10}$

Contributions such as these have the potential to impact credibility assessment across a number of indicators, including considerations relating to level of detail and external consistency. Therefore, the RMAs' communicative practices are understood as

\footnotetext{
${ }^{9}$ Mary Crock and Laurie Berg, Immigration, Refugees and Forced Migration: Law, policy and practice in Australia (Federation Press, 2011) ch 19.

${ }^{10}$ Italics in quotes indicate the interviewee's emphasis.
} 
drawing on superior knowledge of the institution's procedures and expectations. This superior knowledge also informs their perceived role as mediators.

\section{Mediation}

The RMAs identified a role as mediators 'trying to translate what the client says into a format that will be digestible and understood by the decision-maker' (P07). This mediation role is bi-directional, with RMAs also 'sort of trying to imagine what it looks like for someone reading it for the first time' (P01) and explaining the procedures and law based on this.

It also entails pre-empting the decision-maker's responses, especially when credibility may become an issue. This influences advice and preparation.

P05 You want to ask about [...] inconsistencies, obviously, about if there's some notable delays in their story, perhaps it doesn't make sense [...] I think we would apply a similar logical framework to how the department might assess that but a lot more charitably than they do.

Therefore, in an attempt to pre-empt or curtail any likely credibility issues, the RMAs reported applying similar evaluative processes to those that would be undertaken by decision-makers, albeit more generously. This means that while they may be critical of credibility assessment processes and other aspects of the migration regime, the RMAs are nonetheless influenced and constrained by these structures in how they advise their clients and in assessing the strength of their applications. This uncovers a potential tension between RMAs' roles as advocates for their clients and as immigration gatekeepers. ${ }^{11} \mathrm{~A}$ key concern is that by implementing this gatekeeper role, even though it may ultimately increase a client's chances of success, the asylumseeker's agency to tell their story in their own way may be at risk. ${ }^{12}$ However, framing any suspicions or concerns they may have in this way was seen as acting to protect their relationship with their clients and rapport-building. Addressing these concerns as early as possible was seen as crucial, in order to avoid apparent inconsistencies or other types of credibility concerns. Timing more generally was considered an important consideration

\footnotetext{
${ }^{11}$ For a similar argument in another legal setting, see Shonna L Trinch, Latinas' Narratives of Domestic Abuse: Discrepant versions of violence (John Benjamins Publishing, 2003).

${ }^{12}$ See also Vogl (n 6).
} 


\section{Timing and form}

Timing was also a factor in RMAs' preparations of application/appeal documents. Some reported providing their written submissions, outlining relevant country information and legal arguments at the time of submitting the application forms or some time before the interview (eg, P02, P04). Others indicated that their normal practice was to only provide written submissions after the interview (P01, P05-P07).

The latter group argued that this helps focus the content of submissions because, based on the interview, they would know which points need addressing. They described sometimes strategically varying the timing of their submissions, for example, pre-empting a particularly problematic element and wanting to 'throw everything at them early' (P05). The content and timing of submissions also depend on available resources. P07 explained that having student volunteers meant she could sometimes organise more detailed background submissions, drawing on third-party country information to include with an application where, in other cases, limited time would mean she only provided a submission after the interview, and only when clearly necessary.

RMAs also differed in their strategies regarding oral submissions made during interviews or hearings. Sometimes this was framed as stylistic: 'I want to go for, pithy, short take away things that I think [will]gut punch them if I can' (P05). Once again, as mediators, these choices are informed by the expected reception of the decisionmaker.

Content or level of detail also determined whether RMAs would raise an argument or issue in person or later in written submissions. For example, P06 notes for apparent interpreting issues that have given rise to perceived inconsistency or other credibility concerns, she would likely wait to discuss these with the client and prepare a written explanation. Conversely, P07 prefers addressing such issues promptly.

P07 When it comes to credibility issues, particularly credibility issues that have arisen because of miscommunication, I would always address it at the interview because I don't want that decision-maker to walk away with that [...] what I think is an incorrect impression and just leave it [until] written submissions... [...] and then it's always a bit... it's a judgement call as to whether you ask the client to clarify it with the officer [...] or whether you yourself clarify it. 
Whatever the ultimate decision, P07 assigned herself responsibility for addressing the issue, either directly through her own speech or indirectly by alerting the client to the issue and advising them how to address it.

P04 similarly provided a number of examples where he has intervened to offer explanations related to particular cultural practices or knowledge about the country of origin which his clients were unable to provide, to clarify what otherwise appeared to be unexpected, implausible behaviour. He chose to intervene in situations where he had specific knowledge to offer, but did so in a way that acknowledged decision-maker authority over the interaction. For example, he described his contribution when a client was unable to explain why he could not obtain a copy of his aunt's German passport.

P04 This simple thing yeah ... and he was struggling and he was just, the case officer, the member was thinking, why is he ... so [argumentative] about a simple thing... then I said if I could intervene, and the member said yes go ahead. I said you know, sir, that in Afghanistan, for, to get a passport or some documents, or Taskera or ID cards of a relative....it's very difficult...

P02 differed in her approach, reporting rarely making oral submissions or intervening in hearings, and focused on interventions to explain the decision-maker's communication to the client, rather than addressing the decision-maker's potential misunderstanding.

P02 You're not there to speak on behalf of the client, you're just there to make sure that the member is following the process, $[. .$.$] so you can't really interject too$ often, [...] unless you feel like the member isn't explaining things well enough... you can say, look I think you should repeat the question, [...] is there another way that you can explain that or can I interrupt and explain it to the client in a different way, and normally that's fine, [...] but ... yeah I just think of all the clients that wouldn't have [...] lawyers there to do that and suddenly that puts a huge amount of stress on them.

This approach reflects in some way the limited legal or procedural right that RMAs have to actively participate in interviews and hearings. ${ }^{13}$ Decision-makers can vary in

\footnotetext{
${ }^{13}$ Case officers may decide whether or not to allow an RMA to participate in departmental interviews, and what form that participation will take, but are advised that they 'should be aware that is in the interest of maintaining procedural fairness and good client service to allow the RMA to attend an interview, unless there is a specific
} 
their preferences: they may allow the RMA to make some sort of oral submissions before the end of the session. However, this is not universally granted, and sometimes the RMA may be excluded from the interview, as occurred in one example given by P03.

\section{Rapport building}

Building rapport with clients was seen as another important element of RMAs' work. Participants believed that developing a relationship of trust and respect helped clients feel more comfortable when disclosing sensitive information and increased their confidence in the RMA's advice, thereby impacting their communication. This can help promote the timely inclusion of important details about the refugee narrative, thus avoiding omissions or delays that can harm credibility.

Resources and strategies to build rapport also draw on communication skills. For example, knowledge of the client's first language is often considered beneficial, to 'have that direct connection' (P03). But a shared linguistic and ethnic identity was also perceived as creating challenges:

P01 What can we say? A shy, gay Iranian man ... they'd probably feel more comfortable coming out to a non-Iranian lawyer, where there's just none of that cultural background.

Gender can also contribute to this complex dynamic, with some 'clients just not wanting to be represented by a woman, and that's more likely when the woman is from the same ethnic background' (P01).

While the way their clients perceive them impacts on rapport building, the RMAs adopt responses to best meet their and their client's individual circumstances and traits. P03, who is of Arabic background, explained one strategy she adopts.

P03 I mean I always need to tell them look I don't really care if you [...] have left the Islamic religion. I mean I'm Muslim myself but I'm here to support you and I'm here to support whatever your opinion is and you know, that's, [...] kind of my

reason for excluding them.' See Department of Home Affairs (Cth), Procedures Advice Manual 3: 'Working with the Migration Advice Industry - Procedural Instruction' (30 August 2019). In the AAT, the tribunal member has the power to determine whether a legal representative can be present and how much and when they can speak. There is no strict right for them to appear or speak on behalf of their client. See Migration Act 1958 (Cth) s 366A. Although, for some caveats, see discussion in Crock and Berg (n 9) 591-2. 
job and I personally respect your own religious, you know, whatever view you take... so, I guess what the process is before the hearing is just to say look we're all here because we support your human rights so don't be embarrassed to show everyone what you're thinking or how you feel ... if you're of homosexual identity just express that because no-one's going to judge you that's the sort of thing that I try and convey to them because they're not used to that, they're from a different [...] sort of environment

P06, who is a young female lawyer-RMA, also acknowledged the role that her age and gender could play in how her clients relate to her, noting this as a consideration she makes. Her choices are also influenced by her clients' own backgrounds, explaining, for example, that she would vary how formally she dresses to best maximise the confidence and comfort of her various clients. However, ultimately, having chances to spend time with them, working on their application or appeal, was most crucial, as 'through $[\ldots]$ being a good lawyer for them ... generally, they yeah, come to see and appreciate and trust that' (P06).

Likewise, P02 stressed the importance of having sufficient time with clients, especially when their claims involve traumatic, sensitive experiences. Working through an interpreter also increases the time required to conduct meetings and develop rapport. Finally, bureaucratic constraints add an extra layer of difficulties. For example, there may be delays of years before a decision is handed down, and staff turnover may mean that a single client has multiple RMAs during the course of the application process, requiring extra time and effort to brief, build rapport and respond to client frustration.

The research participants were conscious of these types of structural limitations, but once again identified strategies they use to address them. For example, they stress to clients their independence from the immigration department, and their inability to control timelines. Some mentioned how they remind themselves that it is unrealistic for their clients to fully open up about their experiences, while others described how much they would impress upon them the need to disclose to their RMA as much as they could before submitting their application, explaining some of the procedural (and credibility assessment-related) difficulties associated with adding new information later. 


\section{Managing communication}

RMAs act to manage other people's communication in a variety of ways. One common example mentioned was advising clients on when or whether to use an interpreter. The research participants were universal in their preference for advising clients to request an interpreter for interviews and hearings, even if the clients speak English well.

They explained this preference by referring to the demanding conditions of the interview/hearing, that the client would most likely be nervous and the type of terminology used can be challenging. This preference appears to align with departmental practice, with one participant noting that the Immigration Department will 'always [make] sure that there's an interpreter involved, even if the client does speak English' (P02). Others saw the benefit of interpreting as providing a strategic advantage for applicants who understand English: it gives them more time to formulate their responses when they hear both the original and the interpreted versions.

However, interpreting can also give rise to difficulties, and RMAs identified their responsibility for addressing or avoiding some of these. Similar to other types of interventions, the RMAs reported a range of approaches to intervening and influencing interpreter participation.

They identified choices relating to whether to use a telephone interpreter or in-person interpreter, offering diverse opinions on each, and discussed how they would react in an interview or hearing if they were dissatisfied with the interpreter provided. They discussed practices of requesting interpreters of particular genders or specifying particular dialects. They also identified particular structural/systemic shortcomings in the available options. For example, while they acknowledged that there may be tensions between applicants and interpreters from certain countries of origin or religious backgrounds, they are limited in how they can request interpreters based on these characteristics, because such requests may be viewed as discriminatory (P08). This is the case even when there may be quite real linguistic differences between different language varieties, but the official classification of languages and dialects limits the specificity of the language version requested. For example, P03 noted comprehension issues between Lebanese and Iraqi Arabic speakers, and P08 explained how the only official options for different Arabic types is either Arabic or 
Sudanese Arabic, despite the diversity of varieties of Arabic across the Gulf, the Middle East and North Africa. ${ }^{14}$

Three of the RMAs (P03, P04 and P08) identified specific linguistic skills in client languages which increase their ability to promptly identify interpreting issues during interviews. The other RMAs emphasised closely familiarising themselves with the details of the client's claim to be able to gauge when something goes wrong, sometimes enlisting the client and/or interpreters to go through interview/hearing recordings to identify and prepare a written explanation regarding specific interpreting issues.

The commonality among the RMAs in these cases, as with the above issue of responding to credibility issues or miscommunication, is that they view selecting and managing interpreters as primarily their responsibility. They see themselves as responsible for making specific requests in this regard, in consultation with their clients, and similarly feel responsible for intervening when they identify a misunderstanding, or suspect that an interpreter is not interpreting completely. Still, they expressed difficulty with interrupting a decision-maker or interpreter to correct something, or asking one of the participants to slow down or break up their speech to allow for complete interpreting. This may be due to social dynamics: 'it is very embarrassing' to intervene and correct an interpreter (P04). It may also be a tactical choice involving a judgement call, meaning that the RMA must ask themselves 'is me saying this going to add to their credibility or not, like, ... maybe it's one I can let go if there is a mistranslation, there's such a good rapport here that it's not worth interrupting' (P05). Therefore, the way that RMAs manage communication is likely to be determined by multiple factors, including the individual context and dynamics of an interview, the nature and gravity of the issue, as well as the individual resources of the RMA involved, with a calculation needing to be made based on the likely impacts on credibility.

\section{Conclusion}

RMAs see themselves as active and valuable participants who contribute in myriad ways to what is communicated in an application or appeal, including by helping to

\footnotetext{
${ }^{14}$ See 'Languages available through TIS National', Translation and Interpreting Service (Web Page, last updated 6 February 2018) https://www.tisnational.gov.au/en/Agencies/Help-using-TIS-Nationalservices/Languages-available-through-TIS-National
} 
establish and maintain client credibility and/or effectively respond to potential adverse credibility findings. This finding may seem unsurprising, but it contrasts sharply with the way the application process is framed in other discourse, namely in official guidance on assessing credibility aimed at decision-makers, and also in published decisions, where applicant communication is foregrounded and RMAs' contributions are often backgrounded or invisible. ${ }^{15}$

While this article draws on interviews with a small number of participants, a number of findings flow from the above analysis. Similarities in the research participants' choices reflect the limitations and challenges created by legal and procedural structures. The law determines what they can do, such as when they can speak and in what form. It also determines what they feel they should do. In terms of credibility, this means that even when they are inclined to believe their clients, the RMAs must consider how the Department is likely to view their claims, and must apply what they believe to be the most valuable or appropriate choices in preparing written documents and deciding what supporting evidence to present and when. However, the research demonstrates that RMAs' beliefs about best approaches may differ. Partly this may be influenced by the particular resources each individual has at their disposal, such as language skills and (perceived) identity. Importantly, the diversity of these beliefs, practices and resources indicate the scope for there to be equally diverse experiences and to affect outcomes for the asylum seekers they assist.

Thus, while variety is evident, RMAs' substantial and complex contributions to communication, refugee narrative creation and addressing of credibility concerns demonstrate the many potential ways that professional assistance is likely to impact how asylum seekers navigate RSD processes, and ultimately their success in doing so.

Laura Smith-Khan is a Chancellor's Postdoctoral Research Fellow in the Faculty of Law at the University of Technology Sydney.

\footnotetext{
15 See Smith-Khan, 'Telling Stories: Credibility and the representation of social actors in Australian asylum appeals' (n 1); Smith-Khan, 'Different in the Same Way? Language, diversity and refugee credibility' (n 1).
} 